\title{
The impact of cardiovascular drug innovation on the longevity of elderly residents of Switzerland, 2003-2012
}

\author{
FRANK R. LICHTENBERG ${ }^{1, *}$ \\ ${ }^{1}$ Columbia University, New York, United States; National Bureau of \\ Economic Research, Cambridge, United States; and CESifo, Munich, Germany
}

\begin{abstract}
Previous investigators have argued that one of the two most important contributors to improved human survival is the treatment of cardiovascular disease. Among Swiss inhabitants age 65 and over, 90\% of the 1994-2010 decline in the overall death rate was due to the decline in the rate of deaths from diseases of the circulatory system. Little if any of the decline in cardiovascular mortality is likely to have been due to changes in behavioral risk factors, especially tobacco use and obesity.

This study examines the impact of cardiovascular drug innovation on the longevity of elderly residents of Switzerland using cross-sectional patient-level data on about 22 thousand patients insured by a major health insurer (CSS) during the period 2003-2011. We investigate the effect of the vintage (world launch year) of the cardiovascular drugs used by an individual in 2003 on his or her longevity (time till death), controlling for several demographic characteristics and indicators of health status. We are able to track a patient's vital status until 12/31/2011: 8 years after the end of the period in which cardiovascular drug use (and other variables) are measured.

Our estimates indicate that people who used newer cardiovascular drugs in 2003 had longer time till death than people who used older cardiovascular drugs, controlling for the number of 2003 prescriptions and their distribution by main anatomical group, the number of 2003 doctor visits and their distribution by specialty, whether the person was hospitalized in 2003, sex, and age. Our most conservative estimates imply that cardiovascular drug innovation accounted for almost a quarter of the increase in longevity among elderly residents of Switzerland during 2003-2012, and that it increased their longevity by almost 3 months. Other estimates are about twice as large. All of the estimates are consistent with the hypothesis that newer classes of drugs tend to be therapeutically superior to older classes of drugs, and that newer drugs tend to be superior to older drugs within the same class.

Even our more conservative estimates indicate that the use of new cardiovascular drugs by elderly residents of Switzerland has been highly cost effective. Our conservative estimate of the cost per life-year gained from cardiovascular drug innovation is below $\$ 10,000$, and some economists have argued that the value of a statistical life-year is as high as $\$ 300,000$.
\end{abstract}

JEL Classification: C2, I12, J11, L650, O330

Key words: cardiovascular, Switzerland, mortality, longevity, health, innovation, pharmaceutical

* Correspondence to: Frank R. Lichtenberg, Graduate School of Business, Columbia University, 504 Uris Hall, 3022 Broadway, New York, NY 10027 USA. E-mail: frl1@ columbia.edu

dx.doi.org/10.5617/njhe.1291 


\section{Introduction}

During the period 1994-2010, life expectancy at birth in Switzerland increased by 4 years, from 78.7 to 82.7 , and the standardized death rate per 100,000 Swiss inhabitants declined by 270 , from 1146 to $876 .{ }^{1}$ The standardized rate of deaths from diseases of the circulatory system (ICD-10 Chapter IX) declined by 202, from 510 to $308 .^{2}$ Hence, $75 \%(=202 / 270)$ of the decline in the overall death rate was due to the decline in the rate of deaths from diseases of the circulatory system. ${ }^{3}$ It is reasonable to estimate that the decline in the rate of deaths from diseases of the circulatory system increased life expectancy at birth in Switzerland by 3.0 years $(=75 \% \times 4.0$ years $)$ during the period $1994-2010$. Weisfeldt and Zieman (2007) said that "one of the two most important contributors to improved human survival is the treatment of cardiovascular disease."

Extensive surveys of previous research (Weisfeldt and Zieman (2007), Ford and Capewell (2011)) suggest that, in principle, the substantial decline in Swiss cardiovascular mortality could have been due to two main types of factors. The first type is improvements in behavioral risk factors, ${ }^{5}$ especially tobacco use and obesity. Tobacco consumption has declined in Switzerland: smoking prevalence among permanent residents of Switzerland ages 14-65 declined from 33\% in 2001 to 27\% in 2010 (Swiss Association for Smoking Prevention (2014)). But apparently this has made only a minor contribution to the decline in Swiss cardiovascular mortality: according to the Federal Statistical Office (2009), during the period 1995-2007, the number of smoking-attributable deaths of people age 65 and over declined by only 388 , which is only $13 \%$ of the decline from 23,807 to 20,865 in the number of deaths of people age 65 and over from diseases of the circulatory system. Moreover, during the period 1992-2007, the fraction of the adult Swiss population that was overweight (BMI 25-30) increased from $24.9 \%$ to $29.2 \%$, and the fraction that was obese (BMI > 30) increased from 5.4\% to $8.1 \%$ (Schneider, Venetz and Berardo (2009)).

The second type of factor that previous research suggests may have caused the substantial decline in Swiss cardiovascular mortality is medical innovation: the introduction and use of new medical products and procedures. It is useful to distinguish between two types of medical innovation: pharmaceutical innovation and non-pharmaceutical medical innovation. Weisfeldt and Zieman (2007), argued that "pharmaceutical agents play a major role in prevention of atherosclerosis and its consequences: heart attack, stroke, and heart failure"; "protein enzymes, receptors, or channels identified by the pharmaceutical industry as 'drugable targets' have led to striking, remarkable, and repeated achievement"; and that the "marked reduction in cardiovascular disease and its consequences was largely driven by the development and implementation of drugs for long-term use and by complicated and

\footnotetext{
${ }^{1}$ Sources: Eurostat demo_mlexpec and hlth_cd_asdr tables. Life expectancy and the standardized death rate are closely (inversely) related, since both are based on age-specific death rates.

${ }^{2}$ Cardiovascular disease was the main cause of 21,959 deaths (at all ages) in 2010. (There were 62,649 deaths in Switzerland in 2010.) Cardiovascular disease was a secondary cause of 17,712 deaths (at all ages) in 2010 (Source: Federal Statistical Office (2013)).

${ }^{3}$ Among Swiss inhabitants age 65 and over, 90\% (=947/1050) of the decline in the overall death rate was due to the decline in the rate of deaths from diseases of the circulatory system.

${ }^{4}$ The other contributor was eliminating the scourge of common infectious diseases through public health measures, vaccines, and antibiotic drug development.

${ }^{5}$ The Psychology Dictionary defines a behavioral risk factor as follows: "any particular behavior or behavior pattern which strongly yet adversely affects health. It increases the chances of developing a disease, disability, or syndrome. Examples of these factors include tobaccco use, alcohol consumption, smoking, obesity, physical activity, and sexual activity." http://psychologydictionary.org/behavioral-risk-factor/\#ixzz2rnu5J68P
} 
costly procedures and operations for acute disease management." Ford et al (2007) estimated that $47 \%$ of the decline between 1980 and 2000 in the age-adjusted U.S. death rate for coronary heart disease was due to "treatments," $24 \%$ was due to reductions in total cholesterol, and $20 \%$ was due to reductions in systolic blood pressure. Many of the treatments identified by Ford et al (2007) were pharmaceutical treatments, and pharmaceuticals (e.g. statins) probably also played an important role in reducing cholesterol and blood pressure. Also, Ford and Capewell (2011) argued that "aggressive recommendations regarding targets for cholesterol, glucose, and blood pressure evolved, and the medications available to health care providers to treat these risk factors proliferated for secondary prevention, then increasingly for primary prevention. Revascularization, coronary artery bypass surgery, and percutaneous coronary interventions emerged as evidence-based interventional approaches to chronic disease, then to [acute myocardial infarction], as well."

This study will examine the impact of cardiovascular drug innovation on the longevity of elderly residents of Switzerland using cross-sectional patient-level data on about 22 thousand patients insured by a major health insurer (CSS) during the period 20032011. The basic theory and methodology are discussed in Section 2. Descriptive statistics are presented in Section 3. Empirical results are presented in Section 4. A summary and conclusions are provided in Section 5.

\section{Theory and methodology}

\section{A. Basic hypothesis}

Our basic hypothesis is that longevity (or time till death at a given age) is positively related to the quality of medical goods and services used. The quality of medical goods and services is not directly observable. However, we also hypothesize that, in general, the average quality of newer (later vintage) goods and services is higher than that of older (earlier vintage) goods and services. The hypotheses that vintage has a positive effect on quality, and that quality has a positive effect on longevity, imply that vintage has a positive effect on longevity.

Robert Solow (1960) introduced the concept of vintage into economic analysis. This was one of the contributions to the theory of economic growth that the Royal Swedish Academy of Sciences cited when it awarded Solow the 1987 Alfred Nobel Memorial Prize in Economic Sciences:

Solow's basic idea was that technical progress is "built into" [or embodied in] machines and other capital goods and that this must be taken into account when making empirical measurements of the role played by capital. ${ }^{6}$ This idea then gave birth to the "vintage approach"... Solow's empirical results naturally gave the formation of capital a markedly higher status in explaining the increase in production per employee. The most important aspect of Solow's article was not so much the empirical outcome, but the method of analyzing "vintage capital". Nowadays, the vintage capital concept has many other applications and is no longer solely employed in analyses of the factors underlying economic growth... The vintage approach has proved invaluable, both from the theoretical point of view and in applications..." (Nobelprize.org (2014)).

\footnotetext{
${ }^{6}$ Solow assumed that technical progress is embodied in machines because machine manufacturers perform R\&D. Since the medical substances and devices industry is much more research-intensive than the machinery industry (National Science Foundation (2014)), new medical treatments may embody even more technical progress than new machines.
} 
Subsequently, Grossman and Helpman (1991) argued that "almost every product exists on a quality ladder, with variants below that may already have become obsolete and others above that have yet to be discovered," and that "each new product enjoys a limited run at the technological frontier, only to fade when still better products come along." Harper (2007, p. 103) argued that "new improved models of high-tech equipment that embody improvements are frequently introduced and marketed alongside older models."

\section{B. Econometric model}

We will investigate the effect of the vintage of the cardiovascular drugs used by an individual on his or her longevity (time till death), controlling for several demographic characteristics and indicators of health status. We will do this by estimating models of the following general form:

$$
\ln \left(\text { time_till_death }_{i}\right)=\beta_{1} \text { cardio_drug_vintage } i+\beta_{2} \text { cardio_class_vintage } \mathrm{i}_{i}+\gamma Z_{i}+\varepsilon_{i}
$$

where

time_till_death $\mathrm{i}_{\mathrm{i}}=$ the number of years from 12/31/2003 until the date of death of individual $\mathrm{i}^{7}$

cardio_drug_vintage ${ }_{i}=$ the weighted mean vintage of cardiovascular drugs used by individual i during 2003

cardio_class_vintage $\mathrm{i}_{\mathrm{i}}=$ the weighted mean vintage of the classes of cardiovascular drugs used by individual i during 2003

$\mathrm{Z}_{\mathrm{i}}=\mathrm{a}$ vector of other attributes of individual i (age, sex, and utilization of medical services in 2003)

$\varepsilon_{\mathrm{i}}=$ a disturbance

Eq. (1) will be estimated by weighted least-squares, weighting by the number of cardiovascular drugs used by individual i during 2003.

We are able to track a patient's vital status until 12/31/2011: 8 years after the end of the period in which cardiovascular drug use (and other variables) are measured. If individual i did not die by December 31, 2011, his or her death date is unknown - we only know that the death date was or will be after December 31, 2011. Hence, the variable time_till_death is right-censored. We will estimate versions of eq. (1) using a statistical procedure (the SAS LIFEREG procedure) that fits parametric models to failure time data that can be uncensored, right censored, left censored, or interval censored. We will assume that the number of years from 12/31/2003 until the date of death has the Weibull distribution, one of the most commonly used distributions in failure time analysis. The probability density function of a Weibull random variable $\mathrm{x}$ is:

$$
\begin{aligned}
\mathrm{f}(\mathrm{x} ; \lambda, \mathrm{k}) & =(\mathrm{k} / \lambda)(\mathrm{x} / \lambda)^{\mathrm{k}-1} \exp \left(-(\mathrm{x} / \lambda)^{\mathrm{k}}\right) & & \mathrm{x} \geq 0 \\
& =0 & & \mathrm{x}<0
\end{aligned}
$$

\footnotetext{
${ }^{7}$ As discussed below, this variable is right-censored. Our estimation procedure will account for this.
} 
where $k>0$ is the shape parameter and $\lambda>0$ is the scale parameter of the distribution. ${ }^{8}$ The mean of a Weibull random variable can be expressed as $\lambda \Gamma(1+(1 / \mathrm{k}))$ where $\Gamma(\mathrm{z})$ is the Gamma function: ${ }^{9}$

$$
\Gamma(\mathrm{z})=\int_{0}^{\infty} \mathrm{t}^{\mathrm{z}-1} \mathrm{e}^{-\mathrm{t}} \mathrm{dt}
$$

We assume that the scale parameter $\lambda$ depends on patient characteristics $X$ as follows: $\lambda=$ $\exp (\beta \mathrm{X})$. Hence $\ln \lambda=\beta \mathrm{X}$, and $\ln ($ mean survival time $)=\beta \mathrm{X}+\ln (\Gamma(1+(1 / \mathrm{k})))$. Therefore the estimated coefficient on a patient characteristic $X_{1}$ indicates the percentage change in mean survival time attributable to a unit increase in $\mathrm{X}_{1}$.

Our estimation procedure allows us to use right-censored survival data, but the precision of our estimates will be greater, the larger the fraction of the observations that are not censored. To increase the precision of the estimates, we will analyze people who were 65 years and older ("the elderly") on 1 January 2003. The survival times of $36 \%$ of these people are not censored.

\section{Measurement of drug vintage}

CSS provided data on all outpatient prescription drugs used by each individual during 2003. ${ }^{10}$ In the CSS data, prescriptions are identified by the World Health Organization (WHO)'s Anatomical Therapeutic Chemical (ATC) classification system, which WHO says is "the gold standard for international drug utilization research" (WHO Collaborating Centre for Drug Statistics Methodology (2014)). In the WHO ATC system, active substances (drugs) are divided into different groups according to the organ or system on which they act and their therapeutic, pharmacological and chemical properties. Drugs are classified in groups at five different levels. The drugs are divided into fourteen main groups (1st level), with pharmacological/therapeutic subgroups (2nd level). The 3rd and 4th levels are chemical/pharmacological/therapeutic subgroups and the 5th level is the chemical substance. The 2nd, 3rd and 4th levels are often used to identify pharmacological subgroups when that is considered more appropriate than therapeutic or chemical subgroups. This is illustrated by Table 1, which shows the chemical substances in chemical subgroup C10AA (HMG CoA reductase inhibitors) and the ATC codes and names of their "parents."

Our first measure of cardiovascular drug vintage (the weighted mean vintage of cardiovascular drugs used by individual i during 2003) is defined as follows:

$$
\text { cardio_drug_vintage } \mathrm{i}_{\mathrm{i}}=\left(\sum_{\mathrm{d}} \mathrm{n} \_\mathrm{rx} \text { id } \mathrm{drug} \_\mathrm{year}_{\mathrm{d}}\right) / \Sigma_{\mathrm{d}} \mathrm{n} \_\mathrm{rx} \text { id }
$$

where

$$
\mathrm{n}_{-} \mathrm{rx}_{\mathrm{id}}=\text { the number of prescriptions individual i had for cardiovascular }
$$

\footnotetext{
${ }^{8}$ The shape parameter is what gives the Weibull distribution its flexibility. By changing the value of the shape parameter, the Weibull distribution can model a wide variety of data. If $\mathrm{k}=1$, the Weibull distribution is identical to the exponential distribution; if $\mathrm{k}=2$, the Weibull distribution is identical to the Rayleigh distribution; if $\mathrm{k}$ is between 3 and 4 the Weibull distribution approximates the normal distribution. The Weibull distribution approximates the lognormal distribution for several values of $\mathrm{k}$.

${ }^{9}$ See http://en.wikipedia.org/wiki/Weibull_distribution and www.engineeredsoftware.com/nasa/weibull.htm.

${ }^{10} \mathrm{CSS}$ does not have information about provider-administered drugs, e.g. chemotherapy.

${ }^{11}$ Cardiovascular drugs are drugs in anatomical main group C (cardiovascular system drugs) in the WHO ATC classification system.
} 
drug_year $_{d}=$ the earliest year in which drug $\mathrm{d}$ was registered in seven countries ${ }^{12}$

Our second measure of cardiovascular drug vintage (the weighted mean vintage of the classes (chemical subgroups) of cardiovascular drugs used by individual i during 2003) is defined as follows:

$$
\text { cardio_class_vintage } \mathrm{i}=\left(\Sigma_{\mathrm{d}} \mathrm{n} \_ \text {rx } x_{\text {id }} \text { class_year } \mathrm{d}\right) / \Sigma_{\mathrm{d}} \mathrm{n} \_\mathrm{rx} \text { id }
$$

where

class_year ${ }_{\mathrm{d}}=$ the earliest year in which any drug in drug d's class (chemical subgroup) was registered in seven countries

If all drugs (chemical substances) within the same class (chemical subgroup) are "therapeutically equivalent, ${ }^{13}$ a patient's longevity should not depend on cardio_drug_vintage, conditional on cardio_class_vintage, i.e. $\beta_{1}=0$ and $\beta_{2}>0$ in eq. (1). If newer drugs tend to be therapeutically superior to older drugs within the same class, and newer classes of drugs tend to be superior to older classes of drugs, the estimates of $\beta_{1}$ and $\beta_{2}$ should both be positive and significant.

Table 1: Chemical substances in chemical subgroup C10AA (HMG CoA reductase inhibitors) and the ATC codes and names of their "parents"

\begin{tabular}{lll}
\hline ATC level & ATC code & ATC name \\
\hline 1 (anatomical main group) & C & Cardiovascular system \\
2 (therapeutic subgroup) & C10 & Lipid modifying agents \\
3 (pharmacological subgroup) & C10A & Lipid modifying agents, plain \\
4 (chemical subgroup) & C10AA & HMG CoA reductase inhibitors \\
5 (chemical substance) & C10AA01 & Simvastatin \\
5 (chemical substance) & C10AA02 & Lovastatin \\
5 (chemical substance) & C10AA03 & Pravastatin \\
5 (chemical substance) & C10AA04 & Fluvastatin \\
5 (chemical substance) & C10AA05 & Atorvastatin \\
5 (chemical substance) & C10AA06 & Cerivastatin \\
5 (chemical substance) & C10AA07 & Rosuvastatin \\
5 (chemical substance) & C10AA08 & Pitavastatin \\
\hline
\end{tabular}

\footnotetext{
${ }^{12}$ The seven countries are Canada, Denmark, Iceland, Norway, Sweden, Switzerland, and the USA. WHO ATC codes and registration dates are reported in regulatory information of the first six countries. The U.S. FDA does not use WHO ATC codes, but a link between FDA New Drug Application numbers and WHO ATC codes was obtained from the Institut de Pharmacologie Moléculaire et Cellulaire (IPMC)'s chemoinfo database http://chemoinfo.ipmc.cnrs.fr/MOLDB/index.html. We are grateful to Dominique Douguet of IPMC for providing us with those data.

${ }^{13}$ According to one medical dictionary, drugs that have "essentially the same effect in the treatment of a disease or condition" are therapeutically equivalent. Drugs that are therapeutically equivalent may or may not be chemically equivalent, bioequivalent, or generically equivalent. http://medical-dictionary.thefree dictionary.com/therapeutic+equivalent
} 


\section{Other potential determinants of longevity}

If the vintage of cardiovascular drugs used were strongly correlated across individuals with other determinants of longevity, failure to control for those other determinants would bias estimates of the effect of cardiovascular drug innovation on longevity. In all of the time till death models we estimate, we will control for the person's birth year and sex. In some models, we will also control for the person's utilization of ambulatory and inpatient care and prescription drug use in 2003. Controlling for these variables is an imperfect way of controlling for the person's initial health status, i.e. his or her health status in 2003. (The CSS data do not include any direct measures of health status, such as data on self-reported health status, activity limitations, or disability days.) It is quite possible that controlling for the quantity of medical care used in 2003 will cause estimates of the effect of cardiovascular drug innovation on longevity to be conservative. The evidence indicates that (1) people who used more medical care in 2003 had shorter life expectancy, and (2) that people who used newer cardiovascular drugs in 2003 used less medical care in 2003. If (2) is partly due to the fact that using newer cardiovascular drugs contributes to better health, which in turn leads to less utilization of medical care, ${ }^{14}$ controlling for the quantity of medical care used will result in underestimation of the effect of cardiovascular drug innovation on longevity.

Ideally, we would like to control for other potential determinants of longevity in eq. (1), such as measures of socioeconomic status (e.g. income and education) and use of nonpharmaceutical medical innovations.However, previous studies have shown that controlling for measures of socioeconomic status does not reduce estimates of the effect of pharmaceutical innovation on longevity. In his analysis of longitudinal country-level data on 30 developing and high-income countries, Lichtenberg (2013a) found that controlling for income, education and other factors did not reduce (and in some cases even increased) the effect of drug vintage on longevity. In his analysis of patient-level data on elderly Americans, Lichtenberg (2012) found that controlling for an extensive set of attributes (the mean year the person started taking his or her medications, which may serve as a proxy for mean duration of medical conditions; race; education; family income as a percent of the poverty line; insurance coverage; Census region; marital status; and over 100 medical condition dummy variables) had virtually no effect on estimates of the effect of drug vintage on longevity.

The apparent insensitivity of estimates of the effect of pharmaceutical innovation on longevity to controlling for socioeconomic factors may be due to the fact that heterogeneous pharmaceutical treatment of patients is primarily due to physician practice variation. Wennberg (2004) argues that "unwarranted [treatment] variation-variation not explained by illness, patient preference, or the dictates of evidence-based medicine-is a ubiquitous feature of U.S. health care." A large number of studies have documented the importance of unexplained variation in medical care in general and prescribing behavior in particular. Wennberg and Wennberg (2000) examined variation in nine drugs or classes of drugs among members of Blue Cross and Blue Shield of Michigan, and argued that "evidence does not, per se, ensure that pharmaceuticals are always used rationally." Lee et al (2008) showed that "pediatric and adult transplant physicians differed significantly in their

\footnotetext{
${ }^{14}$ Data derived from 1996-2010 U.S. Medical Expenditure Panel Surveys suggests that cardiovascular drugs may be subject to a "quality-quantity tradeoff": cardiovascular conditions with larger increases in mean drug vintage tended to have smaller increases in the mean number of prescriptions per patient. Also, Lichtenberg (2014) found that medical conditions that had larger increases in the number of new (post-1990) drugs per person in the U.S. during the period 1996-2010 tended to have larger declines in use of almost all non-drug medical services.
} 
management strategies for chronic myeloid leukemia, acute and chronic graft-versus-host disease, and choice of graft source for patients with aplastic anemia. Among adult transplant physicians, there was little agreement on the patient factors favoring reduced intensity conditioning or myeloablative conditioning." DeSalvo et al (2000) reported "wide variation... in assignment of reappointment interval with mean return intervals... ranging from 2.2 to 20.5 weeks. Sex was a significant provider independent variable... Female providers assigned earlier reappointment intervals for their patients." Solomon et al (2003) found that "established risk factors for NSAID-associated gastrointestinal toxicity were poor predictors of who was prescribed a selective COX-2 inhibitor; in contrast, physician prescribing preference was an important determinant." De Las Cuevas et al (2002) showed that "there is a remarkable degree of variation in antidepressant prescribing by psychiatrists and general practitioners; this is due to economic and social factors as much as to morbidity differences." Rochon et al (2007) found that "residents in facilities with high antipsychotic prescribing rates were about 3 times more likely than those in facilities with low prescribing rates to be dispensed an antipsychotic agent, irrespective of their clinical indication." 15 Zink et al (2001) found that "trends in the drug management of [rheumatoid arthritis] are adopted differentially by the members of the rheumatology community." Davis and Gribben (1995) found that "data from a survey of general practice in New Zealand confirm the existence of extensive variability in prescribing. Controlling for patient, diagnostic, and practitioner variables...does not reduce the extent of interpractitioner variability in prescribing rates." Moreover, de Jong et al (2009) found that decision support systems do not reduce variation in prescribing. Lichtenberg (2012) found that drug vintage is not significantly related to several important individual attributes, including insurance coverage, race, and family income as a percent of the poverty line, and that only $1 / 8$ of the variation in drug vintage is explained by the presence or absence of more than 100 medical conditions and key demographic and socioeconomic variables.

Pharmaceutical innovation is not the only type of medical innovation that is likely to increase longevity. Other medical innovation, such as innovation in diagnostic imaging, surgical procedures, and medical devices, is also likely to increase longevity. Therefore, it would be ideal to include measures of the vintage of non-pharmaceutical medical goods (e.g. devices) and procedures in eq. (1). ${ }^{16}$ Unfortunately, CSS does not have data on the medical procedures performed on their patients. But failure to control for nonpharmaceutical medical innovation is unlikely to bias estimates of the effect of pharmaceutical innovation on premature mortality, for several reasons.

First, the number of people exposed to pharmaceutical innovation tends to be much larger than the number of people exposed to other types of medical innovation: for example, in $2007,62 \%$ of Americans consumed prescription drugs, while only $8 \%$ of Americans were admitted to hospitals. ${ }^{17}$ Second, pharmaceuticals are more research-intensive than other

\footnotetext{
${ }^{15}$ Using clinical and administrative data obtained from all facilities in a Department of Veterans Affairs integrated service network, Krein et al (2002) showed that there was variation in diabetes practice patterns at the primary care provider, provider group, and facility levels, and that the greatest amount of variance tended to be attributable to the facility level.

${ }^{16}$ Lichtenberg (2013d) investigated the effect of hospital procedure innovation on Western Australian patients.

${ }^{17}$ Source: U.S. Medical Expenditure Panel Survey, 2007 Full Year Consolidated Data File. Lichtenberg (2013d) found that therapeutic procedure innovation increased the life expectancy of Western Australia hospital patients (whose mean life expectancy was about 10 years) by 2 to 3 months between 2000 and 2007 . Since the fraction of the population that is hospitalized is fairly low, the implied contribution of hospital procedure innovation to aggregate longevity growth is fairly modest-much smaller than estimates of the contribution of pharmaceutical innovation to aggregate longevity growth.
} 
types of medical care: in 2007, prescription drugs accounted for $10 \%$ of U.S. health expenditure (Center for Medicare and Medicaid Services (2013: Table 2)), but more than half of U.S. funding for biomedical research came from pharmaceutical and biotechnology firms (Dorsey et al (2010)). Much of the rest came from the federal government (i.e. the $\mathrm{NIH}$ ), and new drugs often build on upstream government research (Sampat and Lichtenberg (2011)).

Third, previous research based on U.S. data indicates that non-pharmaceutical medical innovation is not positively correlated across diseases with pharmaceutical innovation. In Appendix 2 of Lichtenberg (2013b), it is shown that, in the U.S. during the period 1997-2007, the rate of pharmaceutical innovation was not positively correlated across diseases with the rate of medical procedure innovation and may have been negatively correlated with the rate of diagnostic imaging innovation. Also, Lichtenberg (2013c) found that estimates of the effect of pharmaceutical innovation on U.S. cancer mortality rates were insensitive to the inclusion or exclusion of measures of non-pharmaceutical medical innovation. This suggests that failure to control for other medical innovation is unlikely to result in overestimation of the effect of pharmaceutical innovation on longevity growth.

\section{Descriptive statistics}

CSS provided data on 38,842 individuals age 65 and over in 2003. About 9\% (3483) of these individuals disenrolled from CSS prior to 12/31/2011; since their date of death is unknown, they were excluded from the sample. Data on the age distribution of the sample are shown in Table 2. Almost two thirds of the sample is female. The mean age of the women (76.63) is 1.43 years higher than that of the mean (75.20).

Table 2: Age distribution of the sample

\begin{tabular}{lccccc}
\hline & $\mathrm{N}$ & Mean & Std Dev & Minimum & Maximum \\
\hline Both sexes & 35359 & 76,12 & 7,6 & 65 & 106 \\
Females & 22634 & 76,63 & 7,77 & 65 & 106 \\
Males & 12725 & 75,2 & 7,19 & 65 & 101 \\
\hline
\end{tabular}

We estimated the time till death model (eq. (1)) for both sexes combined and separately by sex using the right-censored time_till_death observations, and no explanatory variables (only an intercept). This provided estimates of the Weibull shape and scale parameters $(k$ and $\lambda)$ and of mean survival time $(\lambda \Gamma(1+(1 / \mathrm{k}))$. These estimates, along with data on Swiss life expectancy in 2003 at ages 75, 76, and 77, are shown Table 3.

Estimated mean time till death of sample individuals is substantially larger than life expectancy in 2003 as reported in Swiss life tables, especially among women. Estimated mean time till death of women (17.2 years) is $47 \%$ greater than the life-table-based estimate of the life expectancy (11.8 years) of women at the mean age of women in the sample (76.63). Estimated mean time till death of men (14.1 years) is $35 \%$ greater than the lifetable-based estimate of the life expectancy (10.4 years) of men at the mean age of men in the sample (75.20). ${ }^{18}$ A small part of these discrepancies are likely to be due to the fact that

\footnotetext{
${ }^{18}$ Other estimates indicate that the life expectancy of a female CSS enrollee is about $43 \%$ higher than the life expectancy of a male CSS enrollee of the same age (e.g. age 75). In contrast, Swiss life tables indicate that the life expectancy of a 75 year old Swiss woman is about $21 \%$ higher than the life expectancy of a 75 year old Swiss man.
} 
mean time till death is a cohort life expectancy, whereas the life-table-based estimates are period life expectancies (Office for National Statistics (2014)). As noted earlier, the parameters we want to estimate $\left(\beta_{1}\right.$ and $\left.\beta_{2}\right)$ are estimates of the percentage changes in life expectancy resulting from one-year changes in cardio_drug_vintage and cardio_class_vintage, respectively. To be conservative, we will multiply these estimated percentage changes by life-table-based estimates of mean life expectancy to obtain estimates of the absolute changes in life expectancy resulting from one-year changes in cardio_drug_vintage and cardio_class_vintage, respectively.

Table 3: Comparison of sample-based estimates of mean survival time with life-tablebased estimates of Swiss life expectancy in $\mathbf{2 0 0 3}$

\begin{tabular}{lccccccc}
\hline & & & \multicolumn{3}{c}{ Life expectancy in 2003 at: } \\
\cline { 5 - 8 } & scale $(\lambda)$ & shape $(\mathrm{k})$ & $\begin{array}{c}\text { mean time till death } \\
(\lambda \Gamma(1+(1 / \mathrm{k}))\end{array}$ & age 75 & age 76 & age 77 & $\begin{array}{c}\text { mean age } \\
\text { of sample }\end{array}$ \\
\hline Both sexes & 16,62 & 1,10 & 16,0 & 12,0 & 11,3 & 10,6 & 11,2 \\
Females & 17,93 & 1,11 & 17,2 & 13,0 & 12,2 & 11,5 & 11,8 \\
Males & 14,55 & 1,09 & 14,1 & 10,5 & 9,9 & 9,3 & 10,4 \\
\hline
\end{tabular}

Note: Data on Swiss life expectancy in 2003 at ages 75, 76, and 77 were obtained from the Eurostat demo_mlexpec table.

In order to have a full year of data on prescription drug and other medical care use, we also excluded patients who died before $1 / 1 / 2004$. As shown in Table 4, 63.8\% of the remaining 33,569 individuals were alive as of 12/31/2011.

Since our objective is to estimate the impact of cardiovascular drug innovation on longevity, only individuals with at least one cardiovascular drug prescription in 2003 were included in the sample. 23,686 (67\%) of the individuals who died after 12/31/2003 had at least one cardiovascular drug prescription in 2003. ${ }^{19}$ Quantiles of the distribution of individuals with any 2003 cardiovascular drug prescriptions, by number of 2003 cardiovascular drug prescriptions, are shown in Table 5. As shown in Table 6, cardiovascular system drugs was the WHO ATC anatomical main group that accounted for the largest number of 2003 prescriptions among people with any 2003 cardiovascular drug prescriptions: $25 \%$ of the drugs they took were cardiovascular system drugs. ${ }^{20}$

${ }^{19}$ Data from the Norwegian Prescription Database (http://www.norpd.no/) indicate that in 2012, 66\% of Norwegians age 65 and over used cardiovascular drugs:

\begin{tabular}{rrrr}
\hline age & $\begin{array}{r}\text { cardiovascular drug } \\
\text { users per 1000 inhabitants }\end{array}$ & $\begin{array}{r}\text { number } \\
\text { of inhabitants }\end{array}$ & $\begin{array}{r}\text { number } \\
\text { of users }\end{array}$ \\
\hline $65-69$ & 578.8 & 265,511 & 153,690 \\
$70-74$ & 662.7 & 176,039 & 116,669 \\
$75-79$ & 726.1 & 132,735 & 96,373 \\
$80-84$ & 753.4 & 111,402 & 83,934 \\
$85-89$ & 736.8 & 76,583 & 56,427 \\
$90+$ & 650.5 & 46,292 & 30,112 \\
$65+$ & 664.4 & 808,562 & 537,205 \\
\hline
\end{tabular}

\footnotetext{
${ }^{20}$ Even if we include prescriptions of people who did not have any 2003 cardiovascular drug prescriptions, cardiovascular system drugs was the WHO ATC anatomical main group that accounted for the largest number of 2003 prescriptions: $22 \%$ of all prescriptions were for cardiovascular system drugs.
} 
Table 4: Distribution of elderly CSS enrollees who died after $12 / 31 / 2003$, by year of death

\begin{tabular}{lrr}
\hline Year of death & Frequency & $\begin{array}{r}\text { Percent of total } \\
\text { frequency }\end{array}$ \\
\hline 2004 & 1699 & $5,10 \%$ \\
2005 & 1592 & $4,70 \%$ \\
2006 & 1503 & $4,50 \%$ \\
2007 & 1518 & $4,50 \%$ \\
2008 & 1383 & $4,10 \%$ \\
2009 & 1486 & $4,40 \%$ \\
2010 & 1548 & $4,60 \%$ \\
2011 & 1409 & $4,20 \%$ \\
2012 or later & 21431 & $63,80 \%$ \\
Total & 33569 & $100,00 \%$ \\
\hline
\end{tabular}

Table 5: Quantiles of the distribution of individuals with any 2003 cardiovascular drug prescriptions, by number of 2003 cardiovascular drug prescriptions

\begin{tabular}{lr}
\hline $100 \%$ Max & 66 \\
$95 \%$ & 22 \\
$75 \%$ Q3 & 11 \\
$50 \%$ Median & 6 \\
$25 \%$ Q1 & 3 \\
$5 \%$ & 1 \\
$1 \%$ & 1 \\
\hline
\end{tabular}

Note: The mean number of 2003 cardiovascular drug prescriptions among people with any 2003 cardiovascular drug prescriptions was 8.3 .

Table 6: Distribution of 2003 prescriptions by anatomical main group of CSS enrollees who had any 2003 cardiovascular drug prescriptions

\begin{tabular}{lrr}
\hline WHO ATC anatomical main group & $\begin{array}{r}\text { Number of } \\
\text { prescriptions in } \\
\mathbf{2 0 0 3}\end{array}$ & $\begin{array}{r}\text { Percent of } \\
\text { prescriptions in } \\
\mathbf{2 0 0 3}\end{array}$ \\
\hline C CARDIOVASCULAR SYSTEM & 199750 & $25,1 \%$ \\
N NERVOUS SYSTEM & 162091 & $20,4 \%$ \\
A ALIMENTARY TRACT AND METABOLISM & 120355 & $15,1 \%$ \\
M MUSCULO-SKELETAL SYSTEM & 72687 & $9,1 \%$ \\
R RESPIRATORY SYSTEM & 50537 & $6,4 \%$ \\
B BLOOD AND BLOOD FORMING ORGANS & 47553 & $6,0 \%$ \\
D DERMATOLOGICALS & 41226 & $5,2 \%$ \\
S SENSORY ORGANS & 39097 & $4,9 \%$ \\
J ANTIINFECTIVES FOR SYSTEMIC USE & 24409 & $3,1 \%$ \\
G GENITO URINARY SYSTEM AND SEX HORMONES & 18395 & $2,3 \%$ \\
H SYSTEMIC HORMONAL PREPARATIONS, EXCL. SEX & 12961 & $1,6 \%$ \\
HORMONES AND INSULINS & & $0,5 \%$ \\
L ANTINEOPLASTIC AND IMMUNOMODULATING AGENTS & 3813 & $0,3 \%$ \\
V VARIOUS & 2281 & $0,1 \%$ \\
P ANTIPARASITIC PRODUCTS, INSECTICIDES AND & 549 & \\
REPELLENTS & & $100,0 \%$ \\
Total & 795704 & \\
\hline
\end{tabular}


Figure 1 illustrates the nature of cardiovascular drug innovation in Switzerland during the period 2003-2012. It shows the shares of 2003 and 2012 CSS prescriptions for the top 15 cardiovascular system drugs, ranked by number of prescriptions in 2012. As shown in Figure 2, the 2003-2012 change in a drug's market share tends to be positively related to the drug's vintage. The mean vintage of cardiovascular drugs and drug classes used by elderly (age 66+) CSS enrollees during the period 2003-2012 is shown in Figure 3. On average, the drugs used in 2003 were 24 years old, and the drug classes used were 32 years old. Between 2003 and 2012, the mean vintage of drugs used increased 5.3 years, and the mean vintage of drug classes used increased 4.9 years.

Figure 1: Shares of 2003 and 2012 prescriptions of top 15 cardiovascular system drugs, ranked by number of prescriptions in 2012

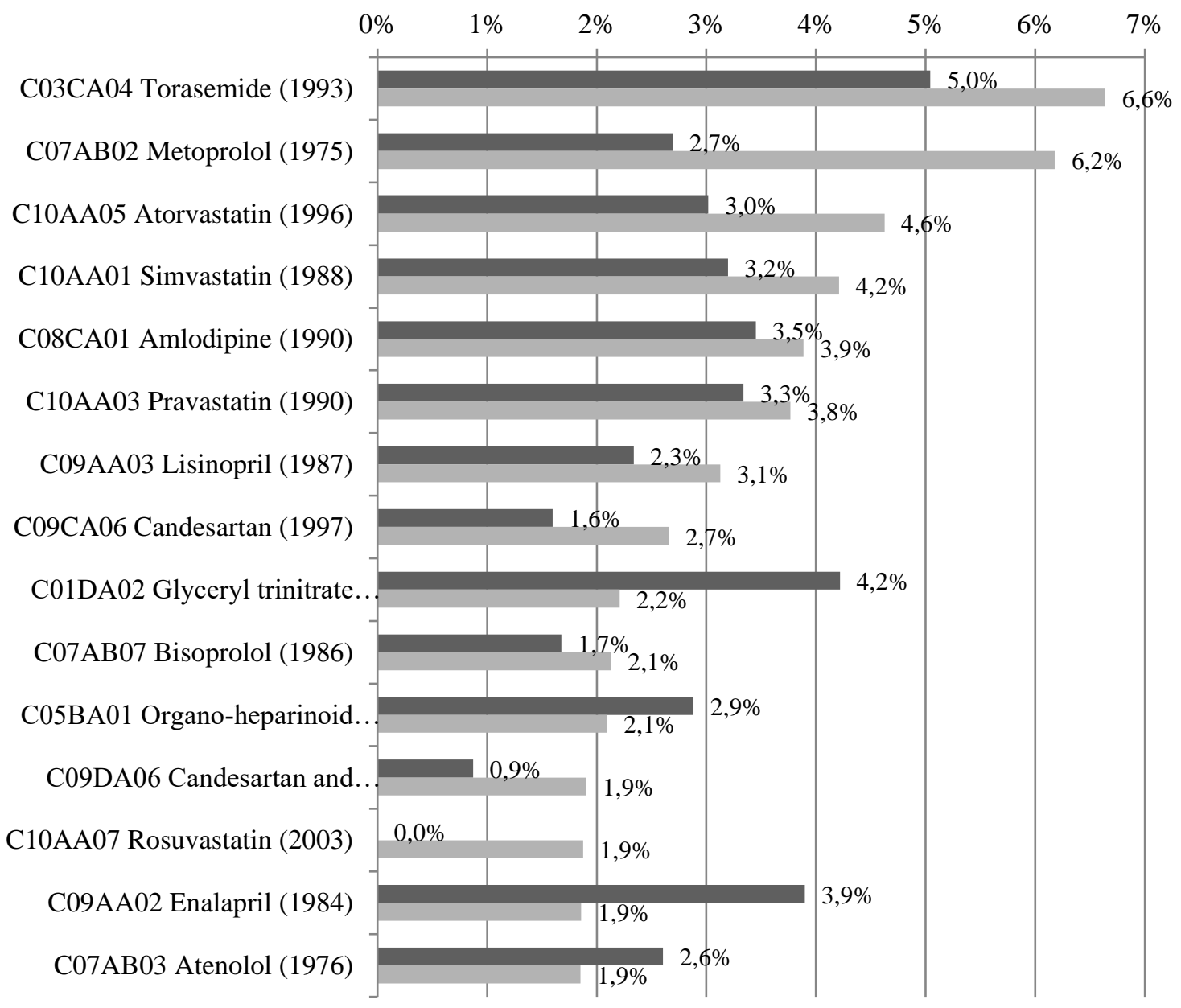

- \% of 2003 prescriptions $\%$ of 2012 prescriptions 
Figure 2: Relationship between drug vintage and 2003-2012 change in its share of cardiovascular drug prescriptions

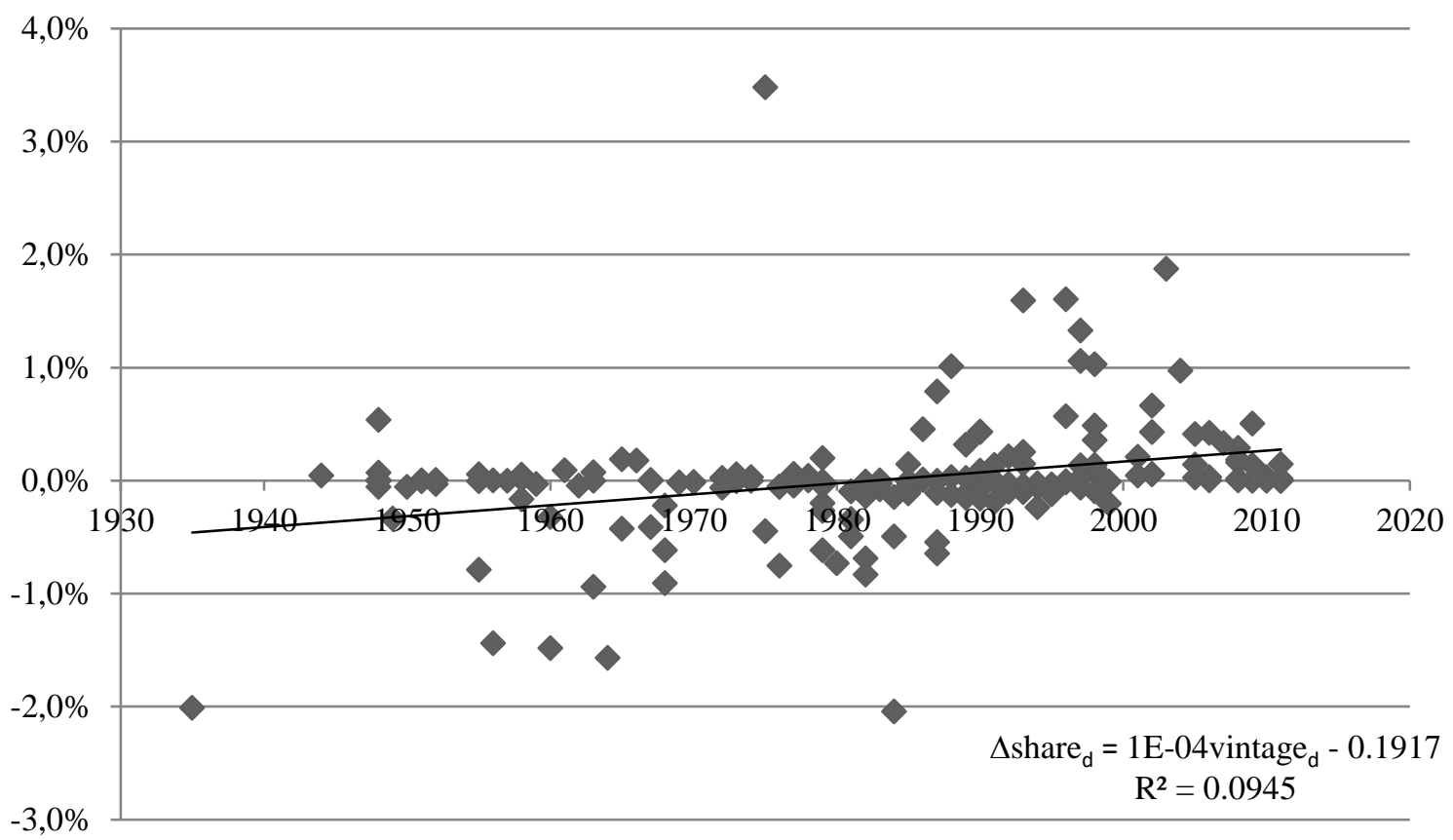

Figure 3: Mean vintage of cardiovascular drugs and drug classes used by elderly (age 66+) CSS enrollees, 2003-2012

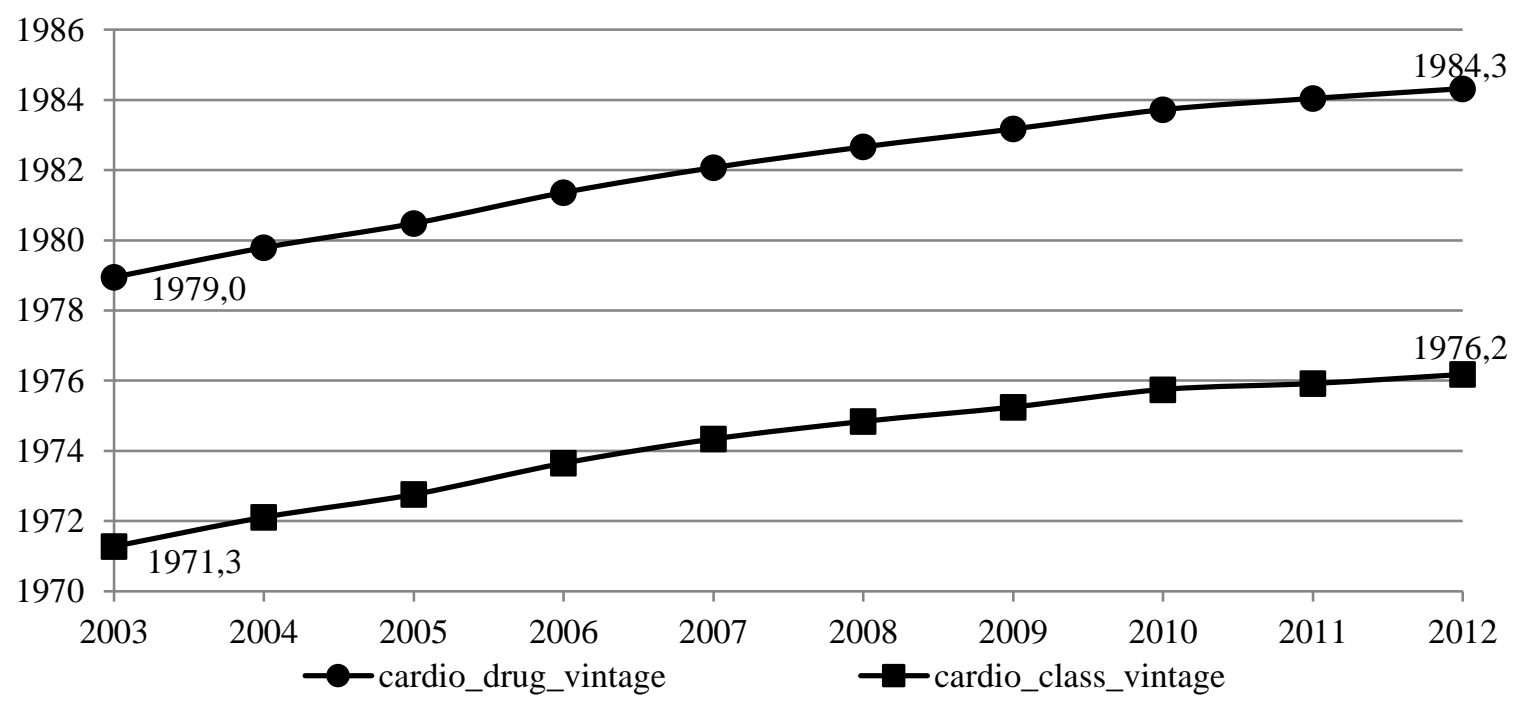

Note: The average annual number of cardiovascular drug prescriptions used by elderly CSS enrollees was 277 thousand. 
Figure 4 depicts the relationship between the age of the patient and the mean vintage of the cardiovascular drugs he or she used. Older patients tend to use older drugs: the drugs used by patients age 90 and over were about 10 years older than the drugs used by 65 year old patients. Drugs used by women were about 1.4 years older than the drugs used by men.

Table 7 shows summary statistics on the vintage of cardiovascular drugs and drug classes and quantity of medical services used in 2003. Panel A of the table shows unweighted statistics (means, standard deviations, and correlation coefficients); panel B of the table shows statistics weighted by the number of 2003 cardiovascular prescriptions. People who used newer cardiovascular drugs and drug classes tended to use less medical care: ${ }^{21}$ they were less likely to be hospitalized, they had fewer doctor visits, and they had fewer prescriptions for both cardiovascular drugs and drugs in general. Drug vintage is more strongly inversely related to the number of prescriptions than it is to the number of doctor visits or to whether the patient was hospitalized. As noted earlier, the inverse relationship between the vintage and quantity of drugs may be partially attributable to a "quality-quantity tradeoff': patients using newer drugs may require fewer drugs.

In some of the versions of eq. (1) we will estimate, $\mathrm{Z}$ will include both the total number of physician visits and the percentage distribution of those visits by specialty. Table 8 shows the distribution of 2003 ambulatory visits by specialty of CSS enrollees who had any 2003 cardiovascular drug prescriptions.

Figure 4: Relationship between age of patient and cardiovascular drug vintage

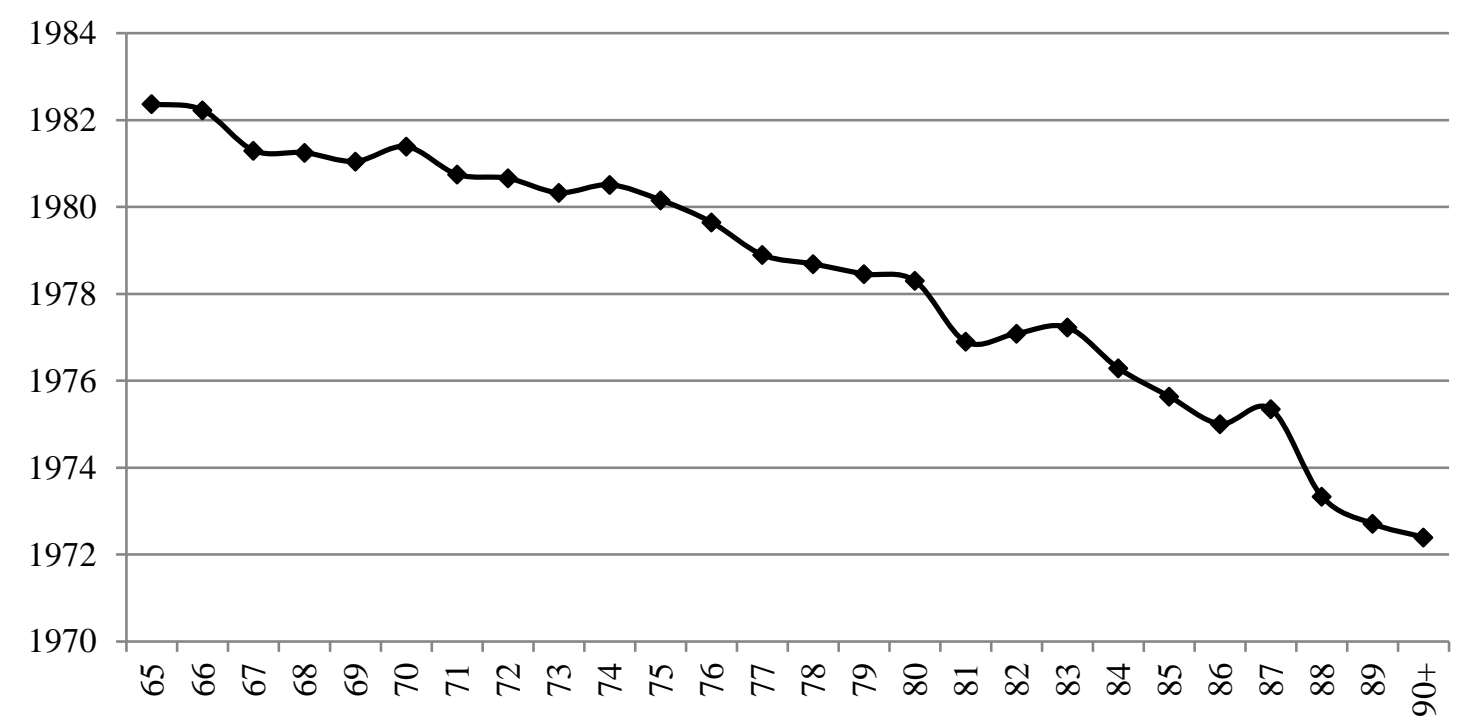

Age of patient

${ }^{21}$ This is partly due to the fact that (as shown in Figure 4) people who used newer cardiovascular drugs and drug classes tended to be younger, and younger people tend to use less medical care. 
Table 7: Summary statistics: vintage of cardiovascular drugs and drug classes and quantity of medical services used in $2003(\mathrm{~N}=\mathbf{2 3 , 6 8 6})$

Panel A. Unweighted means, standard deviations, and correlation coefficients

\begin{tabular}{|c|c|c|c|c|c|c|c|}
\hline$\underline{\text { Statistic }}$ & Variable & $\begin{array}{r}\text { cardio_drug } \\
\text { _vintage } \\
\end{array}$ & $\begin{array}{r}\text { cardio_class } \\
\text { _vintage }\end{array}$ & $\begin{array}{r}\text { Number } \\
\text { of } 2003 \\
\text { rx's } \\
\end{array}$ & $\begin{array}{l}\text { Number of } \\
2003 \text { cardio- } \\
\text { vascular rx's }\end{array}$ & $\begin{array}{r}\text { Number } \\
\text { of } 2003 \\
\text { doctor } \\
\text { visits } \\
\end{array}$ & $\begin{array}{r}2003 \text { hospitaliz- } \\
\text { ation flag }(=1 \text { if } \\
\text { hospitalized, } \\
=0 \text { if not } \\
\text { hospitalized })\end{array}$ \\
\hline MEAN & & 1979,73 & 1972,35 & 33,59 & 8,28 & 5,33 & 0,26 \\
\hline STD & & 11,63 & 12,95 & 25,68 & 6,90 & 3,35 & 0,44 \\
\hline CORR & cardio_drug_vintage & 1,00 & 0,82 & $-0,17$ & $-0,11$ & $-0,05$ & $-0,07$ \\
\hline CORR & cardio_class_vintage & 0,82 & 1,00 & $-0,20$ & $-0,14$ & $-0,08$ & $-0,08$ \\
\hline CORR & Number of 2003 rx's & $-0,17$ & $-0,20$ & 1,00 & 0,57 & 0,41 & 0,2 \\
\hline CORR & $\begin{array}{l}\text { Number of } 2003 \\
\text { cardiovascular rx's }\end{array}$ & $-0,11$ & $-0,14$ & 0,57 & 1,00 & 0,19 & 0,1 \\
\hline CORR & $\begin{array}{l}\text { Number of } 2003 \text { doctor } \\
\text { visits }\end{array}$ & $-0,05$ & $-0,08$ & 0,41 & 0,19 & 1,00 & 0,2 \\
\hline CORR & $\begin{array}{l}2003 \text { hospitalization } \\
\text { flag (= } 1 \text { if hospitalized, } \\
=0 \text { if not hospitalized) }\end{array}$ & $-0,07$ & $-0,08$ & 0,23 & 0,14 & 0,20 & 1, \\
\hline
\end{tabular}

B. Weighted by number of 2003 cardiovascular prescriptions

\begin{tabular}{|c|c|c|c|c|c|c|c|}
\hline$\underline{\text { Statistic }}$ & c Variable & $\begin{array}{r}\text { cardio_drug } \\
\text { _vintage }\end{array}$ & $\begin{array}{r}\text { cardio_class } \\
\text { vintage }\end{array}$ & $\begin{array}{r}\text { Number } \\
\text { of } 2003 \\
\text { rx's } \\
\end{array}$ & $\begin{array}{l}\text { Number of } \\
2003 \text { cardio- } \\
\text { vascular rx's }\end{array}$ & $\begin{array}{r}\text { Number } \\
\text { of } 2003 \\
\text { doctor } \\
\text { visits } \\
\end{array}$ & $\begin{array}{r}2003 \text { hospitaliz- } \\
\text { ation flag }(=1 \text { if } \\
\text { hospitalized, } \\
=0 \text { if not } \\
\text { hospitalized) }\end{array}$ \\
\hline MEAN & & 1978,65 & 1970,89 & 45,72 & 14,03 & 5,86 & 0,31 \\
\hline STD & & 29,43 & 32,13 & 89,68 & 27,09 & 9,94 & 1,33 \\
\hline CORR & cardio_drug_vintage & 1,00 & 0,82 & $-0,26$ & $-0,26$ & $-0,05$ & $-0,07$ \\
\hline CORR & cardio_class_vintage & 0,82 & 1,00 & $-0,29$ & $-0,30$ & $-0,07$ & $-0,08$ \\
\hline CORR & Number of 2003 rx's & $-0,26$ & $-0,29$ & 1,00 & 0,63 & 0,37 & 0,25 \\
\hline CORR & $\begin{array}{l}\text { Number of } 2003 \\
\text { cardiovascular rx's }\end{array}$ & $-0,26$ & $-0,30$ & 0,63 & 1,00 & 0,19 & 0,18 \\
\hline CORR & $\begin{array}{l}\text { Number of } 2003 \text { doctor } \\
\text { visits }\end{array}$ & $-0,05$ & $-0,07$ & 0,37 & 0,19 & 1,00 & 0,20 \\
\hline CORR & $\begin{array}{l}2003 \text { hospitalization } \\
\text { flag (= } 1 \text { if hospitalized, } \\
=0 \text { if not hospitalized) }\end{array}$ & $-0,07$ & $-0,08$ & 0,25 & 0,18 & 0,20 & 1,00 \\
\hline
\end{tabular}


Table 8: Distribution of 2003 ambulatory visits by specialty of CSS enrollees who had any 2003 cardiovascular drug prescriptions

\begin{tabular}{lrr}
\hline Specialty & $\begin{array}{r}\text { Number of } \\
\text { 2003 visits }\end{array}$ & $\begin{array}{r}\text { Percent of } \\
\text { 2003 visits }\end{array}$ \\
\hline GP & 63845 & $39,7 \%$ \\
internal medicine & 33986 & $21,1 \%$ \\
ophthamology & 17763 & $11,0 \%$ \\
gynecology & 5457 & $3,4 \%$ \\
cardiology & 5253 & $3,3 \%$ \\
dermatology and venerology & 4527 & $2,8 \%$ \\
rheumatology & 4309 & $2,7 \%$ \\
radiology & 4031 & $2,5 \%$ \\
oto-rhino-laryngology & 3482 & $2,2 \%$ \\
orthopedic surgery & 3274 & $2,0 \%$ \\
urology & 3071 & $1,9 \%$ \\
surgery & 2120 & $1,3 \%$ \\
gastroenterology & 2109 & $1,3 \%$ \\
pneumology & 2106 & $1,3 \%$ \\
hematology & 1887 & $1,2 \%$ \\
neurology & 1475 & $0,9 \%$ \\
endocrinology and diabetology & 1210 & $0,8 \%$ \\
anesthesiology & 592 & $0,4 \%$ \\
neurosurgery & 247 & $0,2 \%$ \\
angiology & 49 & $0,0 \%$ \\
\hline Total & 160793 & $100,0 \%$ \\
\hline
\end{tabular}

\section{Empirical results}

Weighted least-squares estimates of key parameters of four versions of eq. (1) are presented in Table 9. ${ }^{22}$ All four models include cardio_drug_vintage, cardio_class_vintage, and sex and single-year-of-age dummies. Model 1 does not include any other variables. The estimates of $\beta_{1}$ and $\beta_{2}$ are both positive and highly significant (p-value $\left.<.0001\right)$. This indicates that, controlling for sex and age, people who used newer classes of cardiovascular drugs, and newer drugs within classes, had longer time till death than people who used older classes of cardiovascular drugs, and older drugs within classes.

Model 2 also includes a dummy variable indicating whether the person had been hospitalized in 2003; the log of the number of doctor visits in 2003; and the percentage distribution of those doctor visits by specialty. ${ }^{23}$ As expected, the coefficients on the hospitalization dummy and the log of the number of doctor visits are negative and highly significant: people who were hospitalized and who visited the doctor most frequently in 2003 had lower life expectancy as of the end of 2003. But controlling for these variables has virtually no effect on the cardio_class_vintage coefficient and reduces the cardio_drug_vintage coefficient by less than $20 \%$.

${ }^{22}$ Estimates of all parameters of the most inclusive estimated version (model 4) are presented in Appendix Table 1.

${ }^{23}$ The physician specialty classification is shown in Table 8 . 
Table 9: Estimates of eq. (1): $\ln \left(\right.$ time_till_death $\left.h_{i}\right)=\beta_{1}$ cardio_drug_vintage $e_{i}+\beta_{2}$ cardio_class_vintage $i_{i}+\gamma Z_{i}+\varepsilon_{i}$

\begin{tabular}{|c|c|c|c|c|}
\hline Model & 1 & 2 & 3 & 4 \\
\hline \multicolumn{5}{|l|}{ cardio drug vintage } \\
\hline Estimate & 0,0046 & 0,0038 & 0,0036 & 0,0031 \\
\hline ChiSquare & 102,67 & 68,57 & 60,58 & 45,45 \\
\hline $\operatorname{Pr}>$ Chi & $<.0001$ & $<.0001$ & $<.0001$ & $<.0001$ \\
\hline \multicolumn{5}{|l|}{ cardio class vintage } \\
\hline Estimate & 0,0076 & 0,0077 & 0,0023 & 0,0028 \\
\hline ChiSquare & 319,41 & 318,91 & 27,72 & 39,68 \\
\hline $\operatorname{Pr}>\mathrm{Chi}$ & $<.0001$ & $<.0001$ & $<.0001$ & $<.0001$ \\
\hline \multicolumn{5}{|l|}{2003 hospitalization dummy $(1=$ yes, $0=$ no $)$} \\
\hline Estimate & & $-0,3875$ & $-0,2996$ & $-0,2710$ \\
\hline ChiSquare & & 4158,22 & 2519,83 & 2041,26 \\
\hline $\operatorname{Pr}>\mathrm{Chi}$ & & $<.0001$ & $<.0001$ & $<.0001$ \\
\hline \multicolumn{5}{|l|}{$\underline{\ln (\text { no. of } 2003 \text { doctor visits) }}$} \\
\hline Estimate & & $-0,1263$ & 0,0348 & 0,0235 \\
\hline ChiSquare & & 537,34 & 37,92 & 17,34 \\
\hline $\operatorname{Pr}>\mathrm{Chi}$ & & $<.0001$ & $<.0001$ & $<.0001$ \\
\hline \multicolumn{5}{|l|}{$\underline{\ln \text { (no. of } 2003 \text { prescriptions) }}$} \\
\hline Estimate & & & $-0,3910$ & $-0,3948$ \\
\hline ChiSquare & & & 5692,48 & 4702,04 \\
\hline $\operatorname{Pr}>\mathrm{Chi}$ & & & $<.0001$ & $<.0001$ \\
\hline sex, single-year-of-age dummy variables & yes & yes & yes & yes \\
\hline$\%$ distribution of doctor visits, 19 specialties & no & yes & yes & yes \\
\hline $\begin{array}{l}\% \text { distribution of prescriptions, } 13 \text { main } \\
\text { anatomical groups }\end{array}$ & no & no & no & yes \\
\hline $\mathrm{N}$ & 22630 & 22038 & 22038 & 22038 \\
\hline
\end{tabular}

Model 3 also includes the log of the number of prescriptions in 2003. The coefficient on this variable is negative and highly significant: people who consumed more prescriptions in 2003 had lower life expectancy as of the end of 2003, ceteris paribus. Controlling for this variable has virtually no effect on the cardio_drug_vintage coefficient, but it reduces the magnitude of the cardio_class_vintage coefficient by $70 \%$. ( $\beta_{1}$ and $\beta_{2}$ are still highly significant ( $p$-value $<.0001)$ ). Since using newer drugs may reduce the number of prescriptions a person has - the "quality-quantity tradeoff"- estimates of $\beta_{1}$ and $\beta_{2}$ from model 3 may be underestimates of the true effect of cardiovascular drug innovation on longevity. 
Model 4 also includes the percentage distribution of 2003 prescriptions by main anatomical group. ${ }^{24}$ Controlling for these variables has very little effect on the estimates of the other parameters.

Now we will use the estimates of $\beta_{1}$ and $\beta_{2}$ from models 2 and 4 to calculate the contribution of cardiovascular drug innovation to the increase in longevity of elderly residents of Switzerland during the period 2003-2012. The percentage increase in longevity among cardiovascular drug users attributable to cardiovascular drug innovation ( $\left.\Delta \% \mathrm{LE}_{\text {users }}\right)$ is

$$
\Delta \% \mathrm{LE}_{\text {users }}=\beta_{1} \Delta \text { cardio_drug_vintage }+\beta_{2} \Delta \text { cardio_class_vintage }
$$

where $\Delta$ cardio_drug_vintage is the 2003-2012 change in the mean vintage of cardiovascular drugs, and $\Delta$ cardio_class_vintage is the 2003-2012 change in the mean vintage of the classes of cardiovascular drugs. As shown in Figure 3, $\Delta$ cardio_drug_vintage $=5.4$ and $\Delta$ cardio_class_vintage $=4.9$, so $\Delta \% \mathrm{LE}_{\text {users }}=\left(5.4 \times \beta_{1}\right)+\left(4.9 \times \beta_{2}\right)$. Estimates of the percentage increase in longevity among cardiovascular drug users attributable to cardiovascular drug innovation based on models 2 and 4 are:

$\begin{array}{lllll}\text { Model } & \boldsymbol{\Delta} \text { \%LE } \mathbf{L s e r s} & \text { Standard error } & \mathbf{z} \text { Value } & \operatorname{Pr}>|\mathbf{z}| \\ 2 & 0.05840 & 0.001487 & 39.28 & <0.001 \\ 4 & 0.03065 & 0.001545 & 19.84 & <0.001\end{array}$

Model 2 implies that cardiovascular drug innovation increased the longevity of elderly cardiovascular drug users by about 5.8\% during the period 2003-2012. As noted above, 67\% of elderly CSS enrollees used at least one cardiovascular drug in 2003, so model 2 implies that cardiovascular drug innovation increased the longevity of all enrollees by about $3.9 \%$ $(=67 \% \times .058)$ during the period 2003-2012. According to Swiss life tables, life expectancy at age 76 (approximately the mean age of our sample) increased by one year, from 11.3 to 12.3 years, or $8.5 \%$, between 2003 and 2012. Hence estimates of model 2 imply that cardiovascular drug innovation accounted for almost half $(46 \%=3.9 \% / 8.5 \%)$ of the increase in longevity among elderly residents of Switzerland during 2003-2012, and that it increased their longevity by almost 6 months $(=46 \% \times 1.0$ years $)$. Estimates of model 4 (which controlled for the number of prescriptions and their distribution by main anatomical group, as well as for the number of doctor visits and their distribution by specialty, whether the person was hospitalized, sex, and age) imply that cardiovascular drug innovation accounted for almost a quarter of the increase in longevity among elderly residents of Switzerland during 2003-2012, and that it increased their longevity by almost 3 months.

Even the more conservative estimate derived from model 2 indicates that the use of new cardiovascular drugs by elderly residents of Switzerland has been highly cost effective. Mean annual expenditure on cardiovascular drugs among elderly CSS enrollees with a heart condition was 194 USD in 2011. ${ }^{25}$ For a 76-year-old, expected (undiscounted) future

${ }^{24}$ The WHO ATC anatomical main group classification in shown in Table 6.

${ }^{25}$ This figure is reasonably similar to an estimate derived from other data sources. According to the OECD, in 2011 in Switzerland, per capita expenditure on pharmaceuticals was \$531 (US\$ purchasing power parity). According to the Medical Expenditure Panel Survey, in 2011 in the U.S., per capita expenditure on pharmaceuticals by elderly people (age 65 and over) was 2.15 times as great as per capita expenditure on pharmaceuticals by the population as a whole. Hence per capita expenditure on pharmaceuticals by elderly Swiss people may have been about $\$ 1140(=2.15 * \$ 531)$. According to the Norwegian Prescription Database, cardiovascular drugs accounted for $20.9 \%$ of pharmaceutical expenditure by elderly Norwegian residents in 2012. This suggests that per capita expenditure on cardiovascular drugs by elderly Swiss people may have been about $\$ 238(=20.9 \% * \$ 1140)$. 
expenditure on (new and old) cardiovascular drugs is $\$ 2386$ ( $=\$ 194 /$ year $* 12.3$ years). If we use the more conservative estimate of the 2003-2012 longevity gain from cardiovascular drug innovation ( 3 months), and ignore the fact that part of the expenditure was expenditure on old drugs, we obtain an estimate of the cost per life-year gained of $\$ 9544(=\$ 2386 / 0.25$ years). Aldy and Viscusi (2008) estimated that, in the U.S., the average value of (willingness to pay for) a life-year is $\$ 300,000$.

\section{Summary and conclusions}

Previous investigators have argued that one of the two most important contributors to improved human survival is the treatment of cardiovascular disease. Among Swiss inhabitants age 65 and over, $90 \%$ of the 1994-2010 decline in the overall death rate was due to the decline in the rate of deaths from diseases of the circulatory system. Little if any of the decline in cardiovascular mortality is likely to have been due to changes in behavioral risk factors, especially tobacco use and obesity.

This study has examined the impact of cardiovascular drug innovation on the longevity of elderly residents of Switzerland using cross-sectional patient-level data on about 22 thousand patients insured by a major health insurer (CSS) during the period 20032011. We investigated the effect of the vintage (world launch year) of the cardiovascular drugs used by an individual in 2003 on his or her longevity (time till death), controlling for several demographic characteristics and indicators of health status. We were able to track a patient's vital status until 12/31/2011: 8 years after the end of the period in which cardiovascular drug use (and other variables) were measured.

Our estimates indicated that people who used newer cardiovascular drugs in 2003 had longer time till death than people who used older cardiovascular drugs, controlling for the number of 2003 prescriptions and their distribution by main anatomical group, the number of 2003 doctor visits and their distribution by specialty, whether the person was hospitalized in 2003, sex, and age. Our most conservative estimates implied that cardiovascular drug innovation accounted for almost a quarter of the increase in longevity among elderly residents of Switzerland during 2003-2012, and that it increased their longevity by almost 3 months. Other estimates were about twice as large. All of the estimates were consistent with the hypothesis that newer classes of drugs tend to be therapeutically superior to older classes of drugs, and that newer drugs tend to be superior to older drugs within the same class.

Even our more conservative estimate indicated that the use of new cardiovascular drugs by elderly residents of Switzerland has been highly cost effective. Our conservative estimate of the cost per life-year gained from cardiovascular drug innovation was below $\$ 10,000$, and some economists have argued that the value of a statistical life-year is as high as $\$ 300,000$.

\section{References}

Aldy, J.E. and Viscusi, W. K. (2008). Adjusting the value of a statistical life for age and cohort effects. Review of Economics and Statistics, 90(3), 573-581.

Center for Medicare and Medicaid Services (2013). National Health Expenditure Data. www.cms.gov/Research-Statistics-Data-and-Systems/Statistics-Trends-andReports/NationalHealth ExpendData/Downloads/tables.pdf

Davis, P. and Gribben, B. (1995). Rational Prescribing and Interpractitioner Variation: A Multilevel Approach. International Journal of Technology Assessment in Health Care, 11, 428-442. 
de Jong, J. D., Groenewegen, P. P., Spreeuwenberg, P., Westert, G.P. and de Bakker, D. H. (2009). Do decision support systems influence variation in prescription? BMC Health Services Research, Vol 9, article 20, doi: 10.1186/1472-6963-9-2.

De Las Cuevas, C., Sanz, E. J. and De La Fuente, J.A. (2002), Variations in antidepressant prescribing practice: clinical need or market influences? Pharmacoepidemiology and Drug Safety, 11(6), 515-522.

DeSalvo, K. B., Bowdish, B. E., Alper, A. S., Grossman, D. M. and Merrill, W. W. (2000). Physician Practice Variation in Assignment of Return Interval. Archives of Internal Medicine, 160(2), 205-208.

Dorsey, E. R., et al. (2010). Financial Anatomy of Biomedical Research, 2003 - 2008. Journal of the American Medical Association, 303(2), 137-143.

Federal Statistical Office (2009). Smoking-attributable mortality in Switzerland, Estimation for the years 1995 to 2007. www.bfs.admin.ch/bfs/portal/en/index/news/publikationen.html? publication $\mathrm{ID}=3524$

Federal Statistical Office (2013). Cause of death statistics: Death and its main causes in Switzerland. www.bfs.admin.ch/bfs/portal/en/index/news/publikationen.html?publicationID=5179

Ford, E. S. et al. (2007). Explaining the Decrease in U.S. Deaths from Coronary Disease, 19802000. The New England Journal of Medicine, 356(23), 2388-2398.

Ford E. S. and Capewell, S. (2011). Proportion of the Decline in Cardiovascular Mortality Disease due to Prevention Versus Treatment: Public Health Versus Clinical Care. Annual Review of Public Health, 32, 5-22.

Grossman G. M. and Helpman, E. (1991). Quality Ladders in the Theory of Growth. The Review of Economic Studies, 58(1), 43-61.

Harper, M. J. (2007). Technology and the Theory of Vintage Aggregation. In Berndt, E. R. and Hulten, C. R. (eds.) Hard-to-Measure Goods and Services: Essays in Honor of Zvi Griliches Chicago: University of Chicago Press, pp. 99-120.

Krein, S. L., Timothy, P. H., Eve, A. K. and Hayward, R. A. (2002). Whom Should We Profile? Examining Diabetes Care Practice Variation among Primary Care Providers, Provider Groups, and Health Care Facilities. Health Services Research. 37(5), 1159-1180.

Lee, S. J. et al. (2008). Individual Physician Practice Variation in Hematopoietic Cell Transplantation. Journal of Clinical Oncology, 26(13), 2162-2170.

Lichtenberg, F. R. (2012). The Effect of Pharmaceutical Innovation on Longevity: Patient Level Evidence from the 1996-2002 Medical Expenditure Panel Survey and Linked Mortality Publicuse Files. Forum for Health Economics and Policy, 16(1), 1-33.

Lichtenberg, F. R. (2013a). Pharmaceutical Innovation and Longevity Growth in 30 Developing and High-income Countries, 2000-2009. Health Policy and Technology, 3(1), 36-58.

Lichtenberg, F. R. (2013b). The impact of pharmaceutical innovation on longevity and medical expenditure in France, 2000-2009. Economics and Human Biology, 13, 107-127.

Lichtenberg, F. R. (2013c). Has Medical Innovation Reduced Cancer Mortality? CESifo Economic Studies 60(1), 135-177.

Lichtenberg, F. R. (2013d). The impact of therapeutic procedure innovation on hospital patient longevity: Evidence from Western Australia, 2000-2007. Social Science and Medicine, 77, 5059.

Lichtenberg, F. R. (2014). The impact of pharmaceutical innovation on disability days and the use of medical services in the United States, 1997-2010. Journal of Human Capital, 8(4), 432-480.

National Science Foundation (2014). U.S. Corporate R\&D: Volume 1: Top 500 Firms in R\&D by Industry Category, http://www.nsf.gov/statistics/nsf00301/expendit.htm\#intensity

Nobelprize.org (2014). The Prize in Economics 1987. Press Release. www.nobelprize.org /nobel_ prizes/economics/laureates/1987/press.html 
Office for National Statistics (2014). Guide to Period and Cohort Life Expectancy. www.ons.gov.uk/ons/guide-method/method-quality/specific/population-andmigration/demography/ guide-to-period-and-cohort-life-expectancy/index.html

Rochon, P. A., Stukel, T. A, Bronskill, S. E., Gomes, T., Sykora, K., Wodchis, W. P., Hillmer, M., Kopp, A., Gurwitz, J. H. and Anderson, G. M. (2007). Variation in nursing home antipsychotic prescribing rates. Archives of Internal Medicine, 167(7), 676-683.

Sampat, B. N. and Lichtenberg, F. R. (2011). What are the Respective Roles of the Public and Private Sectors in Pharmaceutical Innovation? Health Affairs, 30(2), 332-9.

Schneider, H., Venetz, W., Berardo, C. G. (2009). Overweight and obesity in Switzerland Part 1: Cost burden of adult obesity in 2007. www.blv.admin.ch/dokumentation/00327/05754/ index. html?lang=de\&download=NHzLpZeg7t,lnp6I0NTU04212Z6ln1acy4Zn4Z2qZpnO2Yuq2Z6g pJCFfIJ_fmym162epYbg2c_JjKbNoKSn6A--.

Solomon, D. H., Schneeweiss, S., Glynn, R. J., Levin, R. and Avorn, J. (2003). Determinants of selective cyclooxygenase-2 inhibitor prescribing: are patient or physician characteristics more important? The Amoerican Journal of Medicine 115(9), 715-720.

Solow, R. M. (1960). Investment and technological progress. In: Arrow, K., Karlin, S. and Suppes, P. (eds.) Mathematical Methods in Social Sciences 1959. Stanford: Stanford University Press, pp. 89-104.

Swiss Association for Smoking Prevention (2014). Tobacco consumption figures in Switzerland. www.at-schweiz.ch/en/facts/tobacco-consumption-figures-in-switzerland.html

Weisfeldt, M. L., Zieman, S. J. (2007). Advances In The Prevention And Treatment Of Cardiovascular Disease. Health Affairs, 26 (1), 25-37.

Wennberg, J. E. (2004). Practice Variations and Health Care Reform: Connecting the Dots. Health Affairs, Web exclusives, October 7 2014, doi: 10.1377/hlthaff.var.140.

Wennberg, J. and Wennberg, D. (2000). Practice Variations and the Use of Prescription Drugs. Chapter 7 of the Dartmouth Atlas of Health Care in Michigan. www.bcbsm.com/content/ dam/ public/Consumer/Documents/about-us/dartmouth-atlas.pdf.

WHO Collaborating Centre for Drug Statistics Methodology (2014). www.whocc.no

Zink, A., Listing, J., Ziemer, S. and Zeidler, H. (2001). Practice variation in the treatment of rheumatoid arthritis among German rheumatologists. The Journal of Rheumatology, 28(10), 2201-2208.

(C) 2017 by the author(s). This article is an open access article distributed under the terms and conditions of the Creative Commons Attribution license (http://creativecommons.org/licenses/by/4.0/). 


\section{Appendix}

\section{Table A1: Estimates of all parameters of model 4 in Table 9}

Table A1 (cont.)

\begin{tabular}{|c|c|c|c|c|c|c|c|c|c|c|c|c|c|}
\hline Parameter & Level1 & DF & Estimate & Std Err & $\begin{array}{r}\text { Chi } \\
\text { Square } \\
\end{array}$ & Pr>Chi & Parameter & Level1 & DF & Estimate & Std Err & $\begin{array}{r}\text { Chi } \\
\text { Square } \\
\end{array}$ & Pr>Chi \\
\hline atc_year_c & & 1 & 0,0031 & 0,0005 & 45,45 & $<.0001$ & age_at_baseline & 67 & 1 & 3,3679 & 0,2481 & 184,31 & $<.0001$ \\
\hline class_year_c & & 1 & 0,0028 & 0,0004 & 39,68 & $<.0001$ & age_at_baseline & 68 & 1 & 3,1585 & 0,2479 & 162,34 & $<.0001$ \\
\hline hosp2003 & & 1 & $-0,271$ & 0,006 & 2041,26 & $<.0001$ & age_at_baseline & 69 & 1 & 3,156 & 0,2479 & 162,11 & $<.0001$ \\
\hline ln_visits & & 1 & 0,0235 & 0,0056 & 17,34 & $<.0001$ & age_at_baseline & 70 & 1 & 2,9825 & 0,2477 & 144,99 & $<.0001$ \\
\hline ln_rx & & 1 & $-0,3948$ & 0,0058 & 4702,04 & $<.0001$ & age_at_baseline & 71 & 1 & 3,0859 & 0,2478 & 155,14 & $<.0001$ \\
\hline spec1 & & 1 & $-0,1552$ & 0,0467 & 11,07 & 0,0009 & age_at_baseline & 72 & 1 & 2,9771 & 0,2476 & 144,57 & $<.0001$ \\
\hline spec2 & & 1 & $-0,4791$ & 0,0908 & 27,86 & $<.0001$ & age_at_baseline & 73 & 1 & 2,938 & 0,2475 & 140,86 & $<.0001$ \\
\hline spec3 & & 1 & 1,1952 & 0,5519 & 4,69 & 0,0304 & age_at_baseline & 74 & 1 & 2,7182 & 0,2475 & 120,64 & $<.0001$ \\
\hline spec4 & & 1 & $-0,0076$ & 0,051 & 0,02 & 0,8824 & age_at_baseline & 75 & 1 & 2,6366 & 0,2474 & 113,59 & $<.0001$ \\
\hline spec5 & & 1 & 0,4089 & 0,0628 & 42,35 & $<.0001$ & age_at_baseline & 76 & 1 & 2,5968 & 0,2474 & 110,15 & $<.0001$ \\
\hline spec6 & & 1 & $-0,0181$ & 0,0666 & 0,07 & 0,7861 & age_at_baseline & 77 & 1 & 2,5571 & 0,2474 & 106,85 & $<.0001$ \\
\hline spec7 & & 1 & 0,5894 & 0,0818 & 51,93 & $<.0001$ & age_at_baseline & 78 & 1 & 2,4151 & 0,2473 & 95,36 & $<.0001$ \\
\hline spec8 & & 1 & 1,1245 & 0,0751 & 224,49 & $<.0001$ & age_at_baseline & 79 & 1 & 2,4609 & 0,2473 & 98,98 & $<.0001$ \\
\hline spec9 & & 1 & $-0,4711$ & 0,0589 & 63,97 & $<.0001$ & age_at_baseline & 80 & 1 & 2,3145 & 0,2473 & 87,59 & $<.0001$ \\
\hline spec10 & & 1 & $-0,1178$ & 0,0471 & 6,25 & 0,0124 & age_at_baseline & 81 & 1 & 2,2549 & 0,2473 & 83,14 & $<.0001$ \\
\hline spec11 & & 1 & 0,1298 & 0,0799 & 2,64 & 0,1042 & age_at_baseline & 82 & 1 & 2,2576 & 0,2473 & 83,33 & $<.0001$ \\
\hline spec12 & & 1 & 0,8708 & 0,2549 & 11,67 & 0,0006 & age_at_baseline & 83 & 1 & 2,095 & 0,2473 & 71,77 & $<.0001$ \\
\hline spec13 & & 1 & 0,2515 & 0,0503 & 25,03 & $<.0001$ & age_at_baseline & 84 & 1 & 2,0588 & 0,2474 & 69,26 & $<.0001$ \\
\hline spec14 & & 1 & 0,9029 & 0,0735 & 150,74 & $<.0001$ & age_at_baseline & 85 & 1 & 1,8684 & 0,2473 & 57,06 & $<.0001$ \\
\hline spec15 & & 1 & 0,3728 & 0,0651 & 32,78 & $<.0001$ & age_at_baseline & 86 & 1 & 1,9233 & 0,2474 & 60,44 & $<.0001$ \\
\hline spec16 & & 1 & $-0,2987$ & 0,0556 & 28,9 & $<.0001$ & age_at_baseline & 87 & 1 & 1,7267 & 0,2474 & 48,71 & $<.0001$ \\
\hline spec17 & & 1 & 0,078 & 0,0697 & 1,25 & 0,263 & age_at_baseline & 88 & 1 & 1,7003 & 0,2475 & 47,21 & $<.0001$ \\
\hline spec18 & & 1 & 0,2519 & 0,0551 & 20,94 & $<.0001$ & age_at_baseline & 89 & 1 & 1,5622 & 0,2476 & 39,82 & $<.0001$ \\
\hline spec19 & & 1 & $-0,1228$ & 0,0637 & 3,72 & 0,0538 & age_at_baseline & 90 & 1 & 1,6967 & 0,2476 & 46,95 & $<.0001$ \\
\hline atc_a & & 1 & 2,466 & 0,1609 & 234,92 & $<.0001$ & age_at_baseline & 91 & 1 & 1,4578 & 0,2477 & 34,63 & $<.0001$ \\
\hline atc_b & & 1 & 1,9473 & 0,1601 & 147,87 & $<.0001$ & age_at_baseline & 92 & 1 & 1,5015 & 0,2479 & 36,68 & $<.0001$ \\
\hline atc_c & & 1 & 2,2952 & 0,157 & 213,83 & $<.0001$ & age_at_baseline & 93 & 1 & 1,4554 & 0,2484 & 34,34 & $<.0001$ \\
\hline atc_d & & 1 & 2,3246 & 0,1621 & 205,74 & $<.0001$ & age_at_baseline & 94 & 1 & 1,2451 & 0,2489 & 25,03 & $<.0001$ \\
\hline atc_g & & 1 & 3,7145 & 0,1714 & 469,42 & $<.0001$ & age_at_baseline & 95 & 1 & 1,3437 & 0,2491 & 29,09 & $<.0001$ \\
\hline atc_h & & 1 & 1,8492 & 0,1715 & 116,21 & $<.0001$ & age_at_baseline & 96 & 1 & 1,1107 & 0,2497 & 19,78 & $<.0001$ \\
\hline atc $\_j$ & & 1 & 2,3935 & 0,1728 & 191,95 & $<.0001$ & age_at_baseline & 97 & 1 & 1,2894 & 0,2538 & 25,82 & $<.0001$ \\
\hline atc_1 & & 1 & 0,5099 & 0,1886 & 7,31 & 0,0069 & age_at_baseline & 98 & 1 & 1,1387 & 0,254 & 20,1 & $<.0001$ \\
\hline atc_m & & 1 & 3,2955 & 0,1588 & 430,55 & $<.0001$ & age_at_baseline & 99 & 1 & 0,8631 & 0,2579 & 11,2 & 0,0008 \\
\hline atc_n & & 1 & 2,1274 & 0,1569 & 183,89 & $<.0001$ & age_at_baseline & 100 & 1 & 0,4883 & 0,2692 & 3,29 & 0,0697 \\
\hline atc_p & & 1 & 3,7025 & 0,5471 & 45,8 & $<.0001$ & age_at_baseline & 101 & 1 & 0,5685 & 0,308 & 3,41 & 0,0649 \\
\hline atc_r & & 1 & 2,1023 & 0,1586 & 175,75 & $<.0001$ & age_at_baseline & 102 & 1 & 0,6613 & 0,2693 & 6,03 & 0,0141 \\
\hline atc_s & & 1 & 3,0137 & 0,1607 & 351,53 & $<.0001$ & age_at_baseline & 103 & 0 & 0 & . & . & \\
\hline $\operatorname{sex}$ & $\mathrm{F}$ & 1 & 0,4355 & 0,0063 & 4850,32 & $<.0001$ & age_at_baseline & 105 & 0 & 0 & . & . & \\
\hline $\operatorname{sex}$ & M & 0 & 0 & & . & • & Intercept & & 1 & $-12,8785$ & 0,6672 & 372,59 & $<.0001$ \\
\hline age_at_baseline & 65 & 1 & 3,4768 & 0,2486 & 195,58 & $<.0001$ & Scale & & 1 & 0,7794 & 0,0024 & - & - \\
\hline age_at_baseline & 66 & 1 & 3,2482 & 0,248 & 171,48 & $<.0001$ & Weibull Shape & & 1 & 1,2831 & 0,004 & - & \\
\hline
\end{tabular}

